\title{
La cuarta persona de la Trinidad. La carne fantasmática de Cristo y la dehiscencia extra-ontológica
}

\author{
Germán Osvaldo Prósperi ${ }^{1}$
}

Recibido: 30 de octubre de 2017 / Aceptado: 9 de junio de 2019

Resumen. En este artículo nos proponemos analizar, desde una perspectiva lógica y ontológica, la noción de una "cuarta persona de la Trinidad", tal como aparece en los tratados De fide orthodoxa y De imaginibus de Juan de Damasco. Sostendremos que esta "cuarta persona" pone en cuestión la lógica de la teología trinitaria. En la medida en que es irreductible a lo divino y a lo humano, así como a la materia y al espíritu, la cuarta persona posee una naturaleza extra-ontológica que exige para expresarse, consecuentemente, una cuarta persona extra-gramatical más allá de la sintaxis.

Palabras clave: Cuarta persona de la Trinidad; Cristo; carne; hypostasis; fantasma; Juan Damasceno.

\section{[en] The Fourth Person of the Trinity. The Phantasmatic Flesh of Christ and the Extra-Ontological Dehiscence}

Abstract. The aim of this paper is to analyse, from a logical and ontological perspective, the concept of a fourth person in the Trinity, as it is presented by John of Damascus in De fide orthodoxa and De imaginibus. We argue that this fourth person challenges the logic of the trinitarian theology. Since the fourth person is irreducible to the divine or the human, or to the matter and the spirit, its nature falls beyond the ontology. Consequently, an extra-grammar fourth person, one beyond syntax, is required to verbalise it.

Keywords: Fourth person of the Trinity; Christ; flesh; hypostasis; phantasmatic; John Damascene.

Sumario: 1. Introducción; 2. Ontología; 2.1. Ousia, Hypostasis y Prosōpon en la teología de Juan de Damasco; 2.2 La cuarta persona en el De imaginibus; 3. Lógica; 3.1 La terza persona; 3.2 The fourth person singular; 4. Conclusión; 5. Referencias bibliográficas.

Cómo citar: Prósperi, G.O. (2020): "La cuarta persona de la Trinidad. La carne fantasmática de Cristo y la dehiscencia extra-ontológica", en Revista de Filosofía 45 (2), 301-317.

\footnotetext{
1 Universidad Nacional de La Plata, Argentina gerprosperi@hotmail.com
} 


\section{Introducción}

Es probable que la oposición de Pedro de Antioquía, también conocido como Pedro Fullo, a las tesis elaboradas en el Concilio de Calcedonia encontrara una de sus expresiones más extremas - y curiosas - en la adición del lema "quien fue crucificado por nosotros" al célebre Trisagion. ${ }^{2}$ Durante siglos, a decir verdad, los Padres de la Iglesia habían discutido si este canto de alabanza se refería a la Trinidad o sólo a Cristo. Como sea, para un teólogo como Juan de Damasco, ${ }^{3}$ quien estaba convencido de que el Trisagion aludía a la Trinidad, la inclusión de la cláusula de Pedro no dejaba de resultar inadmisible y absolutamente blasfema. El problema, por supuesto, concernía a la doble naturaleza de Cristo y a la posibilidad - ciertamente herética de elevar la naturaleza humana o carnal al rango de divinidad. El Damasceno estaba tan preocupado por esta posibilidad que consagró al Trisagion un breve capítulo del De fide orthodoxa ${ }^{4}$ en el cual intentaba demostrar que la adición de Pedro significaba la correlativa adición de una "cuarta persona" al interior de la Trinidad:

En consecuencia, nosotros proclamamos blasfema también la adición en el Trisagio realizada por el insano Pedro Fullo, la cual introduce una cuarta persona [tetarton prosōpon] y concibe separadamente al Hijo de Dios, la Potencia del Padre en él subsistente y separadamente aquel que ha sido crucificado, como si fuese otro respecto al "fuerte", o bien supone a la Santa Trinidad como sujeta al sufrimiento y crucifica al Padre y al Espíritu Santo junto con el Hijo (De fide orthodoxa, III,10). ${ }^{5}$

El problema de fondo, para Juan, consistía en convertir a la carne, es decir a la naturaleza humana de Cristo en una hypostasis independiente, como si el Verbo, en lugar de ser una hypostasis en la que conviven dos naturalezas, según el dictum del Concilio de Calcedonia, ${ }^{6}$ se desdoblase más bien en dos hypostaseis, una por cada naturaleza.

La figura de una "cuarta persona" de la Trinidad, por cierto, no es desarrollada por Juan como cuestión filosófica, más allá de su utilización retórica destinada a refutar

2 El Trisagion o Agios $O$ Theos es uno de los himnos centrales de la liturgia de las iglesias orientales. El nombre deriva de las tres invocaciones que se mencionan en la alabanza: "Santo Dios, Santo Fuerte, Santo inmortal, ten piedad de nosotros [Agios o Theos, Agios ischyros, Agios athanatos, eleison imas]". Janet Timbie explica que la adición de Pedro de Antioquía llegó a separar la iglesia copta y otros grupos no calcedónicos, quienes utilizaban la versión de Pedro, del resto de los cristianos: "Antes del Evangelio, se canta el Trisagion, incluyendo la frase 'quien fue crucificado por nosotros', la cual fue añadida por Pedro Fullo, patriarca de Antioquía (d. 490)" (Timbie 2007, p. 105).

3 Sobre el pensamiento y la vida de Juan de Damasco, cfr. Louth (2002); (2007), pp. 197-220; Cross (2000), pp. 69-124; Di Berardino (2000), pp. 233-242.

$4 \quad$ Se trata del cap. 10 del Libro III.

5 Para las citas de Juan de Damasco utilizamos la edición crítica de Bonifatius Kotter consignada en la bibliografía.

6 Se recordará el texto principal del Concilio de Calcedonia (sesión V, definición 34): "se ha de reconocer a uno solo y el mismo Cristo Hijo Señor unigénito en dos naturalezas, sin confusión, sin cambio, sin división, sin separación, en modo alguno borrada la diferencia de naturalezas por causa de la unión, sino conservando, más bien, cada naturaleza su propiedad y concurriendo en una sola persona y en una sola hipóstasis, no partido o dividido en dos personas, sino uno solo y el mismo Hijo unigénito, Dios Verbo Señor Jesucristo, como de antiguo acerca de Él nos enseñaron los profetas, y el mismo Jesucristo, y nos lo ha trasmitido el Símbolo de los Padres." Sobre el Concilio de Calcedonia, cfr. Grillmeier (1975), vol. I, pp. 488-519; Price \& Whitby (2009). Puede consultarse una traducción inglesa de las Actas del Concilio en Price \& Gaddis (2005); el pasaje recién citado corresponde a la p. 204. 
posibles herejías. ${ }^{7}$ Sin embargo, creemos que la noción de una "cuarta persona", aludida ad absurdum o, mejor aún, per viam negationis en los textos del Damasceno, amerita una indagación filosófica en sí misma. En efecto, consideramos que esta "cuarta persona", insinuada en los recodos de los textos de Juan, pone en cuestión, por no decir que disloca por completo, la lógica de la teología trinitaria. El objetivo de este artículo, por lo tanto, consistirá en mostrar cuál es el peligro que encerraba esta cuarta persona en el seno de la teología. Para ello, hemos estructurado este estudio en dos partes: una ontológica y otra lógica. ${ }^{8}$ En la primera, analizaremos la concepción trinitaria propuesta por Juan de Damasco y a la vez la doble naturaleza que caracteriza a Cristo luego de la encarnación. Sólo a partir de estas precisiones teológico-terminológicas será posible comprender la naturaleza ontológica (o, acaso, extra-ontológica) de la cuarta persona. En la segunda parte, desplazaremos el problema al ámbito lingüístico o gramatical. Mostraremos que la cuarta persona de la teología encuentra su correlato gramatical (o, de nuevo, extra-gramatical) en la noción de una cuarta persona que, al igual que en la teología trinitaria, horada la lógica personal de los tres pronombres. La noción de una "cuarta persona del singular" propuesta por el poeta Lawrence Ferlinghetti y retomada luego por Gilles Deleuze, en este sentido, se revela fundamental. Ella representa, en una clave lógica o lingüística, el ser (o el extra-ser) de la cuarta persona que la ontología teológica oculta en su mismo centro.

\section{Ontología}

\subsection{Ousia, Hypostasis y Prosōpon en la teología de Juan de Damasco}

Para comprender la cristología de Juan Damasceno, así como su concepción trinitaria, ${ }^{9}$ es preciso distinguir, en principio, tres términos claves (cada uno de ellos con una larga historia teológica y filosófica): ousia, hypostasis y prosōpon. En el Concilio de Nicea se había establecido que el Padre y el Hijo comparten una misma substancia (homoousios) ${ }^{10}$ Juan respeta este artículo de fe, así como lo establecido en Calcedonia, y sostiene que las tres personas de la Trinidad no se diferencian por su

7 El concepto de cuarta persona de la Trinidad es manejado últimamente por dos líneas teológicas dispares: la tradicionalista, que pretende identificar la cuarta persona con María Corredentora, y la modernista, que identifica la cuarta persona con el ser humano salvado por el sacrificio de Cristo.

8 Es preciso aclarar que ambos registros, el lógico y el ontológico, se superpondrán en varios momentos de este escrito. No obstante, por razones de mayor claridad expositiva, les hemos consignado dos secciones sucesivas e independientes.

9 Sobre el problema de la Trinidad en general, cfr. Régnon (1892). Sobre la Trinidad y la encarnación, cfr. Studer (1993); Kelly (1968), pp. 252-343. Sobre la encarnación en Juan de Damasco, cfr. Unger (1948), pp. 237-249.

10 En efecto, el Concilio de Nicea había establecido que el Hijo era consubstancial al Padre: "Creemos en un solo Dios Padre omnipotente, creador de todas las cosas visibles e invisibles. Y en un solo Señor Jesucristo, el Hijo de Dios, generado unigénito del Padre, es decir de la substancia del Padre, Dios de Dios, luz de la luz, Dios verdadero de Dios verdadero, generado y no creado, consubstancial [homoousios] al Padre, por medio del cual han sido creadas todas las cosas en el cielo y en la tierra, quien ha descendido y se ha encarnado para nosotros y por nuestra salvación, quien se ha hecho hombre, ha padecido y ha resucitado al tercer día, ha subido al cielo y vendrá a juzgar a los vivos y a los muertos. Creemos en el Espíritu Santo" (citado en Ayres 2004, p. 19). Sobre el Concilio de Nicea, cfr. Grillmeier (1975), vol. I, pp. 249-273. Sobre Cristo como imagen consubstancial al Padre, cfr. Prósperi (2019), pp. 243-265. 
naturaleza (ousia o physis), sino porque cada una de ellas constituye una hypostasis o prosōpon particular. ${ }^{11}$ Dicho de otro modo: las tres personas de la Trinidad difieren en tanto hypostaseis o prosōpa pero son idénticas en cuanto a su ousia o physis. El error de varias sectas heréticas, de hecho, consistía en confundir la ousia con la hypostasis. Por eso se trata para Juan de distinguirlas con suma precisión.

Hemos dicho muchas veces que una cosa es la naturaleza y otra la hipóstasis, y que la naturaleza indica el género común y comprensivo de todas las hipóstasis de la misma especie, como por ejemplo 'Dios' u 'hombre', y que en cambio la hipóstasis indica el ser individual, como por ejemplo el Padre, el Hijo, el Espíritu Santo, Pedro, Pablo. Y por lo tanto es preciso saber que la palabra 'divinidad' y la palabra 'humanidad' son indicativas de las naturalezas, o bien de las esencias; en cambio, la palabra 'Dios' y la palabra 'hombre' no conciernen sólo a la naturaleza [...] sino que son utilizadas en relación a la hipóstasis - puesto que lo más particular recibe el nombre de lo más general (De fide orthodoxa, III, 4).

Juan define la ousia, retomando una tradición antigua, como un género universal (en el sentido en que lo es por ejemplo la humanidad o la animalidad), el cual comprende - o puede comprender - diversas especies. La noción de hypostasis, en cambio, designa siempre el principio de la existencia individual y actual de una entidad. De tal manera que la naturaleza o la substancia tienen su existencia particular en las hypostaseis. ${ }^{12}$ El término prosōpon, a su vez, indica en Juan no sólo el principio de existencia individual de una entidad, sino su modo específico de manifestación. ${ }^{13}$ En la cristología de Juan, la noción de hypostasis permite mantener unidas las dos naturalezas de Cristo (divina y humana) y al mismo tiempo asegurar su distinción. De algún modo, el dispositivo hipostático permite aplicar el eslogan propio del dogma cristológico: unir sin confundir y dividir sin separar (cfr. De fide orthodoxa, III, 3). Cristo, entendido como hypostasis, designa el dispositivo que permite articular, sin confundir, la naturaleza divina con la humana.

Por eso decimos que se trata de una unión de dos naturalezas perfectas, la divina y la humana: (una unión) no por homogenización, o por confusión o por mezcla [...]; sino una unión por composición, según la hipóstasis, sin cambios, sin confusión, sin división y sin separación. Y confesamos una sola hipóstasis del Hijo encarnado de Dios en dos naturalezas que son perfectas, predicando la misma hipóstasis de su divinidad y de su

11 En este artículo, usaremos los términos hypostasis y prosōpon como sinónimos, puesto que ambos hacen referencia, como explicaremos en breve, a cada uno de los miembros de la Trinidad.

12 Sobre la distinción entre ousia e hypostasis, cfr. De fide orthodoxa, III, 6.

13 En los años en los que se desarrollaron los Concilios de Nicea y Constantinopla, comenzaron a utilizarse los términos hypostasis y prosōpon para designar a cada uno de los tres partícipes de la única naturaleza o substancia divina del Dios uno y trino. Muchas veces se usaron como sinónimos. En la tradición griega, tendió a prevalecer el término hypostasis; en la latina, el término prosōpon, es decir persona (cfr. Fazzo 1998: 27-33). Anna Zhyrkova, en un artículo dedicado a la noción de hypostasis en Juan Damasceno, explica: “'Hypostasis” posee un significado ontológico: en principio, designa la existencia actual de una entidad. 'Persona', a su vez, refiere a las acciones de un cierto individuo. El término 'persona', con toda claridad, es lógicamente posterior al de 'hypostasis'. En la doctrina de Juan, la hypostasis es el principio de la existencia, mientras que la persona es el modo de manifestarse a sí misma como una cierta hypostasis. De todas maneras, ser una persona no debe ser entendido como algo accidental en relación a la naturaleza de un cierto individuo. Es más bien el modo a través del cual un individuo expresa su esencia propia, ya sea en el caso de una persona humana ya sea en el de una persona divina" (2009, p. 108). 
humanidad y proclamando que las dos naturalezas son conservadas en él después de la unión: no estableciendo a cada una aparte, sino unidas entre sí en una sola hipóstasis compuesta. De hecho, llamamos esencial a la unión, es decir verdadera y no aparente; y además la llamamos esencial no como si las dos naturalezas compusieran una sola naturaleza compuesta, sino porque ellas están unidas verdaderamente entre sí en la única hipóstasis compuesta del Hijo de Dios (De fide orthodoxa, III, 3).

Como se ve, Juan, al igual que tantos otros teólogos fieles a los dogmas establecidos en los diversos Concilios, lucha en dos frentes: por un lado, contra quienes confunden las dos naturalezas de Cristo; por el otro, con quienes las separan. El peligro a conjurar es tanto la confusión o la mezcla de lo humano con lo divino cuanto la separación radical, la dehiscencia ${ }^{14}$ entre la divinidad y la humanidad. La misma estrategia se aplica a las tres hypostaseis o prosōpa de la Trinidad: "unidas sin confusión [asyngytōs] (de hecho son tres, aunque están unidas), y distintas pero sin discontinuidad [kai adiastatōs]" (De fide orthodoxa, III, 5). Por eso Juan aclara rápidamente que el número "tres" que se utiliza para referirse a las hypostaseis/ prosōpa de la Trinidad no supone una discontinuidad o una heterogeneidad en la substancia divina: "el número no produce en ellas una división, una separación, un extrañamiento o un corte [diairesin è diastasin è allotriōsin kai diatomèn]" (De fide orthodoxa, III, 5). Los términos empleados por Juan, así como su reiteración a lo largo del tratado, no son casuales. Confundir las hypostaseis de la Trinidad, de la misma manera que confundir las dos naturalezas de Cristo, era ciertamente blasfemo. Pero el riesgo último y extremo se escondía sobre todo en la separación de las hypostaseis de la Trinidad y particularmente de las naturalezas de Cristo. Los términos enumerados por Juan marcan la operación más temida por la teología: diairesis, diastasis, allotriōsis. Todos indican la acción de separar, de escindir, de extrañar. Y es precisamente en el perímetro herético abierto por estos términos que Juan vuelve a hacer referencia a la cuarta persona de la Trinidad, esta vez para excusarse a sí mismo y no prestarse a malentendidos respecto al objeto de veneración.

Por lo tanto el Cristo es uno solo, Dios perfecto y hombre perfecto, que nosotros veneramos junto al Padre y al Espíritu, con una única veneración junto a su carne inmaculada: y no decimos que su carne no deba ser venerada (de hecho ella es venerada en la única hipóstasis del Verbo que precisamente se ha vuelto hipóstasis para ella), pero por otra parte no prestamos servicio a la creatura (de hecho no la veneramos sólo como carne sino en cuanto unida a la divinidad, puesto que las dos naturalezas son reconducidas 'a la única persona y a la única hipóstasis de Dios el Verbo'). [...] A causa de la divinidad unida a la carne, del Cristo yo venero las dos a la vez: pero no añado una cuarta persona en la Trinidad [ou gar tetarton parentithēmi prosōpon en tē triadi] - ¡Dios no lo permita! - sino que confieso una sola persona del Dios Verbo y de su carne. La Trinidad sigue siendo Trinidad incluso después de la encarnación del Verbo (De fide orthodoxa, III, 8).

14 El término dehiscencia, en botánica, designa la apertura natural del pericarpio de ciertos frutos o de las anteras de un estambre, para dar salida a la semilla o al polen. También es un término utilizado en medicina para designar la apertura de las paredes de una herida. Curiosamente, en el "último" Merleau-Ponty, cumple una función estratégica y se emparenta con otra serie de conceptos, en particular "carne", "quiasmo", "reversibilidad" o "solapamiento" (cfr. Merleau-Ponty 1964, p. 155, 168, 189; Prósperi 2018, pp. 74-80). Volveremos a este término más adelante. 
Se advertirá que esta cuarta persona concierne precisamente a la naturaleza carnal de Cristo. La cuarta persona es la carne, pero entendida en tanto creatura humana (a la vez alma y cuerpo). El riesgo que intenta evitar - y combatir - Juan es el de convertir la naturaleza humana de Cristo en una hypostasis o prosōpon independiente. Por eso insiste en varias oportunidades, como hemos dicho, en la necesidad de no confundir la noción de ousia con la de hypostasis o prosōpon. Cristo es el umbral que deja abierta, en tanto admite una doble naturaleza (humana y divina), la posibilidad de introducir una cuarta persona en la Trinidad. Juan es consciente del riesgo, pero así y todo sostiene que se puede adorar incluso la carne de Cristo. Pero se la adora no en tanto creatura - por eso no se adora la carne de los hombres - sino en tanto unida a la naturaleza divina por medio de la hypostasis.

\subsection{La cuarta persona en el De imaginibus}

Es curioso que la crítica que Juan le dirige a Pedro de Antioquía en relación a la modificación introducida en el Trisagion sea la misma que le dirigen los iconoclastas, en la célebre querella de las imágenes, a los defensores de los íconos, de los cuales el Damasceno era uno de sus principales adalides. ${ }^{15}$ En efecto, en un Concilio organizado por el emperador Constantino V, gran político y versado teólogo, se decretó blasfemo separar la carne de Cristo de su naturaleza divina y producir una imagen de ella como si fuera un mero hombre. Hacer eso significaba privar a la carne de Cristo de su condición deificada y al mismo tiempo, separándola de su condición divina, introducir una cuarta persona en la Trinidad. Leamos uno de los anatemas del Segundo Concilio de Nicea, celebrado en septiembre-octubre de 787:

Si alguien intenta pintar en colores inertes a Dios, el Logos, quien, existiendo en la forma de Dios asume la forma de un sirviente en su propia hipóstasis y se vuelve en todo similar a nosotros, excepto por el pecado, si alguien lo considera como un mero hombre, y busca separarlo de su divinidad inseparable e inmutable, e introduce por lo tanto un cuarto miembro [ex hoc quaternitatem] en la Santa y Viviente Trinidad, anatema (Mansi 1767, p. 343).

Las imágenes conllevaban el peligro de separar las dos naturalezas de Cristo, la divina y la humana, el espíritu y la carne, y de convertir a esta última, en función del soporte material de los íconos, en una cuarta persona [quarta persona] de la Trinidad. Ante esta actitud crítica de los iconoclastas, la respuesta de los defensores de los íconos no se dejó esperar. ${ }^{16}$ En líneas generales, se adujo que esa unión de lo

15 Sobre la querella iconoclasta, cfr. Anastos (1979), pp. 177-188; Hussey (1990); Belting (2009), pp. $193-219$. Asimismo, cfr. la revisión crítica y extensamente documentada de Brubaker (2012).

16 No es nuestra intención, por supuesto, reconstruir los pormenores de la controversia, sino más bien señalar algunos puntos que merecen nuestra atención en función del tema que nos ocupa. Como se sabe, el célebre tratado de Juan de Damasco sobre las imágenes sagradas concentra, de algún modo, gran parte de los argumentos esgrimidos por los iconófilos en su intento de refutar los ataques en contra de la adoración de los íconos. Moshe Barasch, en Icon. Studies in the History of an Idea, enfatiza el lugar central que ha ocupado el Damasceno en la querella iconoclasta: "La defensa teórica de las imágenes, un gran proceso intelectual que eventualmente triunfó en la batalla de Bizancio y dio forma al mundo espiritual de la Cristiandad oriental, no fue obra de un único autor. [...] Hay, sin embargo, una figura en ese proceso intelectual que se destaca con una particular distinción, y es Juan de Damasco. Ningún otro autor ha tenido tanto impacto en los fundamentos teóricos de la creencia en las imágenes sagradas como Juan de Damasco" (1995, p. 187). 
invisible con lo visible o del espíritu con la carne había sido realizada en Cristo. Por eso el eje de la controversia prácticamente se circunscribió a la imagen del Salvador: "Gran parte del debate estuvo centrado en la figura de Cristo, acerca de si su retrato en colores sobre un soporte de madera le hacía justicia por igual a su naturaleza humana y a su naturaleza divina" (Giakalis 2005, p. 5). El argumento central de los iconófilos, por esta razón, se apoyaba en la encarnación. ${ }^{17}$ Era posible representar la divinidad a través de un medio material ya que el mismo Dios se había hecho visible en Cristo. La encarnación, en este sentido, implicaba una redención de la carne misma, lo cual no significaba convertir a la carne en una cuarta persona de la Trinidad. Dice Juan de Damasco en De imaginibus:

Junto con mi Señor y Rey, Lo adoro vestido en el cuerpo, no como si fuese una cobertura o como si constituyese una cuarta persona [ōs tetarton prosōpon] de la Trinidad - ¡Dios no quiera! La carne es divina, y perdura después de su asunción. La naturaleza humana no se perdió en la Trinidad, sino que, así como el Verbo se hizo carne permaneciendo Verbo, así también la carne se hizo Verbo permaneciendo carne, volviéndose, más bien, una con el Verbo a través de la unión. Por lo tanto, me aventuro a crear una imagen del Dios invisible, no en tanto invisible, sino en tanto vuelto visible para nuestra fortuna en carne y sangre. No pinto por eso una imagen de la Divinidad invisible. Pinto la carne visible de Dios [eikōnizō Theou tēn horatheisan sarka], porque es imposible representar un espíritu, y mucho más Dios que es el que da aliento al espíritu (De imaginibus, I, 4).

Los íconos representaban la carne visible de Dios, es decir el Hijo, la imagen arquetípica del Padre. El problema es que el Hijo no era sólo carne, sino carne y espíritu, hombre y Dios. Los iconófilos sostenían, como Juan de Damasco en el pasaje citado, que el registro de lo visible permitía representar icónicamente a la divinidad. Por eso el culto (no idolátrico) de las imágenes era posible sólo después de Cristo.

Antaño, el Dios incorporal nunca fue representado. Ahora, sin embargo, cuando Dios se hizo carne, y conversó con el hombre, yo hago una imagen del Dios que he visto. No adoro la materia, adoro al Dios de la materia, quien se hizo materia por mí, y se dignó habitar en la materia, quien trabajó para mi salvación a través de la materia. La venero, aunque no como Dios (De imaginibus, I, 16).

La afirmación de Juan es fuerte y polémica. Existe una veneración de la materia, aunque no porque represente una divinidad, sino porque fue asumida por el Hijo. La materia no es Dios, y, sin embargo, a partir de la encarnación, es digna de veneración. Juan adora al Dios de la materia, pero el Dios de la materia se ha materializado en Cristo. La encarnación supone, como han notado los Padres - y sobre todo los mismos teólogos iconoclastas - , una deificación de la carne..$^{18}$ No obstante, Juan

17 Explica J. M. Hussey: "En tanto la apología de los íconos provenía de la defensa tradicional de Germanus y Juan de Damasco al desafío cristológico planteado durante el reinado de Constantino V, y entonces de la visión más 'escolástica' de Teodoro Estudita y del Patriarca Nicéforo, había un énfasis creciente acerca del sentido de la Encarnación en relación con la concepción cristiana de la materia y no fue sin rispideces que se le dio su verdadero valor (la espiritualidad monástica tuvo que enfrentar el mismo problema)" (1990, p. 52)

18 Sobre la deificación de la carne, es decir del hombre, tema frecuente en varios Padres de la Iglesia, cfr. Lossky (1967), pp. 94-96; Henry (2000), p. 23. 
aclara siempre que se trata de una veneración de la carne divinizada por Cristo, y no de la carne meramente humana o pecaminosa. Para comprender en profundidad lo que estaba en juego en estas discusiones (literalmente) bizantinas, permítasenos recurrir a un diagrama que vuelve más tangible la estructura de la Trinidad y la doble naturaleza de Cristo.

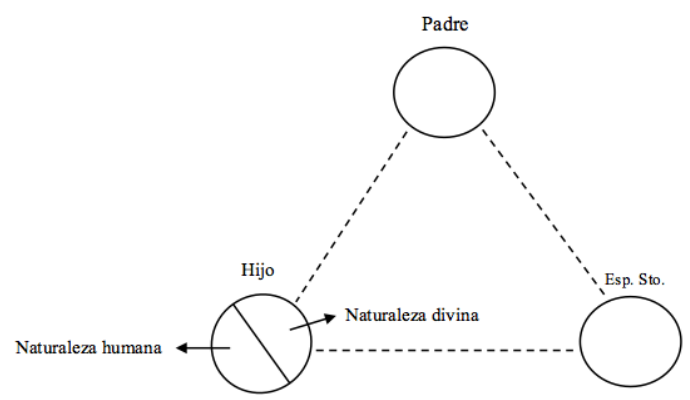

De algún modo, podríamos decir que Juan explica este diagrama en un pasaje del tercer capítulo del Libro III del De fide orthodoxa:

Y, por tanto, siguiendo el principio esencial por el cual las naturalezas del Cristo difieren entre sí - es decir el principio relativo a la substancia - nosotros decimos que él participa con los extremos: según la divinidad, con el Padre y con el Espíritu; según la humanidad, con la madre y con todos los hombres: ya que él mismo es consubstancial según la divinidad con el Padre y con el Espíritu, y según la humanidad con la madre y con todos los hombres (De fide orthodoxa, III, 3).

Ahora bien, creemos que el peligro que afrontaban los teólogos y que circunscribían, muchas veces de forma retórica, en la expresión tetarton prosōpon, se encontraba en el corazón de la segunda hypostasis o prosōpon, en la posibilidad de que se abriera un hiato en el centro de Cristo. Esta cuarta persona, a decir verdad, no sería estrictamente el hombre o la carne humana, según deja suponer el Damasceno, sino una materia o una carne ${ }^{19}$ exenta de toda relación con la creación o el Creador. De este modo, se abriría la posibilidad de pensar, alejándonos ya de Juan de Damasco, una carne (cercana - aunque no idéntica - a la noción de chair merleaupontiana $)^{20}$ que no sería ni el elemento de los cuerpos ni el elemento de los espíritus, ni el elemento de los hombres ni el de los ángeles, sino el intervalo mismo que la hypostasis de Cristo pretendía conjurar. La puerta a la cuarta persona, por eso mismo, no se encuentra en el Espíritu Santo, es decir en la tercera persona, como ha sostenido recientemente Roberto Esposito en la línea de Maurice Blanchot, sino en la segunda, en Cristo. El peligro al que se enfrentaba la teología era la diairesis (la división), la diastasis (la discontinuidad) y la allotriōsis (el extrañamiento). Es en esta dehiscencia que se abre entre divinidad y humanidad, en este intervalo que la hypostasis cristiana intentaba impedir, que se insinúa el rostro o, más bien, la

19 El Damasceno, de hecho, identifica a la carne, en el sentido de naturaleza humana, con la cuarta persona que resulta imperioso conjurar por todos los medios (cfr. De fide orthodoxa, III, 8 y 10; De imaginibus, I, 4).

20 Sobre una concepción cristiana de la carne, en abierta polémica con la perspectiva fenomenológica de MerleauPonty, cfr. Henry (2000). 
máscara de la cuarta persona. Cristo es la cifra de la ambivalencia: la hypostasis (en tanto asegura la unidad de las dos naturalezas) y la anhypostasis, la no-persona (en tanto escinde al hombre de la divinidad). Por eso el Damasceno sostiene que el verdadero peligro que se ocultaba detrás de quienes confundían - o, peor aún, separaban - las dos naturalezas de Cristo consistía en la posibilidad de una desactivación o suspensión de la lógica dogmática de la teología. De tal manera que Cristo, según su aspecto anhypostático, apóstata, ${ }^{21}$ "no se ubicaría ni en la divinidad ni en la humanidad [oute mèn en theotèti esti kai anthrōpotēti], y no sería llamado ni Dios ni hombre [oute de theos onomasthēsetai oude anthrōpos] sino solamente Cristo: y la palabra Cristo no sería nombre de la persona" (De fide orthodoxa, III, 5). Esta estructura, oute...oude, ni...ni, eminentemente neutra (ne-uter: ni/ni) es el verdadero riesgo y el lugar específico de la cuarta persona. Su estatuto ontológico no es el de una substancia, como la divinidad o la humanidad, tampoco el de una hypostasis, como Cristo, el Padre, Pedro o Pablo; de alguna manera, no pertenece a la lógica de la ontología teológica. La anhypostasis, es decir la carne o archi-carne, ${ }^{22}$ la carne apostática, apóstata, no pertenece al Ser tal como ha sido pensado por la metafísica o la ontoteología. En términos estrictos, designa un extra-ser, una región allende al Ser (creador o creado). Para emplear un término de Alexius Meinong, diremos que la cuarta persona es Außersein. ${ }^{23}$ Lo cual significa que no podemos

21 Nos valemos de la distinción que realiza Leoncio de Jerusalén en su tratado Contra Nestorianos, cuando intenta refutar los argumentos que defendían la existencia de dos hypostasis en Cristo. En el segundo libro de su tratado, Leoncio distingue dos sentidos del término hypostasis, uno conjuntivo (sys-stasis) y otro disyuntivo (apo-stasis): "Pero Cristo es llamado más correctamente y más apropiadamente hypostasis (hypo-stasis), puesto que además de ser algo que lo constituye (sys-stasis; literalmente mantener unidos, juntos) también muestra que el individuo subyacente está separado de todos los miembros de la misma especie y de todos los miembros de diferentes especies de acuerdo a sus rasgos específicos, y por lo tanto como una cosa concreta en sí misma, siendo algo que separa (apo-stasis: mantener separado) y que vincula las substancias desvinculadas a fin de constituir el número de cada una respecto a su persona" (II, 1; $P G, 86$, col. 1529D4-11). Sobre Leoncio de Jerusalén, cfr. Krausmüller (2001), pp. 637-657; (2005), pp. 413-447.

22 Como se sabe, Jacques Derrida ha distinguido el "concepto vulgar de escritura" del concepto de "archi-escritura": "Quisiéramos sugerir - leemos en De la grammatologie - que la pretendida derivación de la escritura, por real y mala que sea, no ha sido posible más que bajo una condición: que el lenguaje 'original', 'natural', etc., no haya existido nunca, que nunca haya sido intacto, no tocado por la escritura, que haya sido siempre él mismo una escritura. Archi-escritura de la que nosotros quisiéramos indicar aquí la necesidad y diseñar su nuevo concepto; y que continuamos llamando escritura sólo porque comunica esencialmente con el concepto vulgar de escritura. Éste no ha podido históricamente imponerse más que por el disimulo de la archi-escritura, por el deseo de una palabra que dé caza a su otro y a su doble, que trabaje para reducir su diferencia” (1967, pp. 82-83). Al contrario del concepto empírico o vulgar de escritura, la archi-escritura designa, en Derrida, el espacio de juego y de movimiento de las huellas o trazos: la différance. La noción de archi-carne mantiene la misma relación respecto a la carne que la de archi-escritura respecto a la de escritura. Sólo difiere de la propuesta derrideana por el hecho de haber sobrepasado el margen de la metafísica y por haberse situado, consecuentemente, más allá de la carne y, al límite, más allá del Ser.

23 Meinong sugirió el término Außersein (fuera del Ser o allende al Ser) para referirse a la condición de ciertos objetos que no tenían patria en las regiones de la metafísica tradicional. En efecto, en Über die Stellung der Gegenstandstheorie im System der Wissenschaften, Meinong utilizó el término heimatlos, el mismo que utilizará Heidegger para referirse a la condición del hombre en la época del nihilismo, para calificar a ciertos Objetos que no pertenecían a ningún dominio de la metafísica tradicional (cfr. Meinong 1907, p. 89). Según Meinong, la metafísica occidental se ha limitado a pensar lo real, identificando realidad y ser, a partir de dos niveles fundamentales: un nivel físico (la existencia actual), un nivel psíquico o psicológico (la subsistencia ideal). Si el Ser, para la tradición dogmática de la metafísica (teología cristiana incluida, por supuesto), es o bien físico o bien psicológico, o bien materia o bien espíritu; si, como sostiene Meinong, "la organización de todo el conocimiento en ciencia de la naturaleza y ciencia del espíritu [Natur- und Geisteswissenschaft] [...] sólo toma en consideración la clase de conocimiento que tiene que ver con la realidad [Wirklichkeit]" (1904, p. 7), entonces una singularidad que no se identifica estrictamente ni con un término ni con el otro, ni con lo material 
decir que existe, tal como existen - para la teología - las cosas y los espíritus, los hombres y los ángeles; diremos más bien que subsiste en el límite o por fuera del Ser. Paradójicamente, el término hypostasis ha sido traducido muchas veces por subsistencia, lo cual es justo (hypo: debajo + stasis: mantenerse erguido, yacer). Sin embargo, la teología ha reservado la realidad más eminente a este término, por eso en Juan la hypostasis designa el principio de existencia individual. En el caso de la cuarta persona, en cambio, se trata de una entidad inexistente, pero por eso mismo subsistente en su sentido propio. Su extra-ser se ubica por debajo, o más bien en el medio de la realidad metafísica, entre la materia y el espíritu.

Consideremos las dos modalidades, conjuntiva y disyuntiva, de la segunda hypostasis con mayor detenimiento:

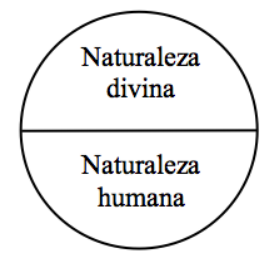

Cristo como coniunctio Sys-stasis

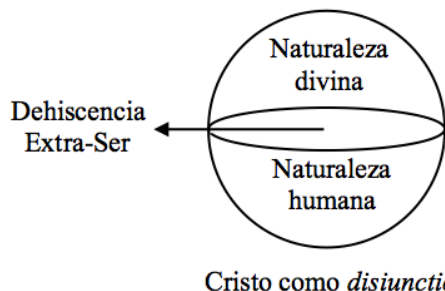

Apo-stasis

El dispositivo hipostático, de este modo, ha funcionado siempre como un aparato de sutura. ${ }^{24}$ La naturaleza divina y la humana se suturan, sin confundirse ni mezclarse, en la hypostasis crística. Este es el aspecto conjuntivo de la hypostasis: la hypo-stasis como sys-stasis. Pero según su sentido disyuntivo, y este es el mayor peligro para la teología, la hypostasis puede lacerarse en su interior, puede devenir apo-stasis y dar lugar a una herida que ninguna coniunctio puede conjurar. El corazón de Cristo, el sagrado corazón, alberga la puerta - la herida - al abismo extra-ontológico. En ese abismo, al interior de la dehiscencia, la palabra Cristo pasaría a designar algo para lo cual faltan quizás los nombres pero que los teólogos, y Juan de Damasco en particular, han identificado con la cuarta persona. El pasaje que hemos citado hace un momento adquiere, entonces, su sentido extremo: "no se ubicaría ni en la divinidad ni en la humanidad, y no sería llamado ni Dios ni hombre sino solamente Cristo: y la palabra Cristo no sería nombre de la persona" (De fide orthodoxa, III, 5).

ni con lo espiritual, ni con el Creador ni con lo creado, no pertenece al Ser (en su sentido metafísico-teológico tradicional), sino que designa un extra-Ser (Außersein), un elemento ajeno a la "realidad" (Außerwirliche). Ahora bien, nos resulta pertinente pensar a la cuarta persona de la Trinidad en los términos de Meinong no sólo porque designa un elemento irreductible a las polaridades metafísicas, sino porque, como veremos en la conclusión, esta carne apóstata coincide con la noción de imagen (y más en concreto de phantasma), un término central en los análisis de Meinong. En efecto, como bien ha indicado Fabián Ludueña Romandini en el excelente prólogo al Pequeño manual de inestética de Alain Badiou, las imágenes poseen una "naturaleza fantasmal [shattenhafte Natur]" (2009, p. 36) que las vuelve irreductibles a las regiones de la metafísica dogmática: "Son existencias que Meinong ha calificado de fantasmales [schattenhaft]" (Ludueña Romandini 2009, p. 36) cuyo estatuto, por eso mismo, concierne más a la sub-sistencia que a la ex-istencia.

24 Sobre la figura de Cristo como aparato de sutura, cfr. Prósperi (2018), pp. 69-71. 


\section{Lógica}

\subsection{La terza persona}

Según Roberto Esposito, la máquina de la teología-política del Occidente posee una estructura bipolar que funciona estableciendo una relación asimétrica y jerárquica entre dos términos a partir de una operación de inclusión exclusiva o de exclusión inclusiva. Esta preeminencia de una lógica dicotómica, en cuyo centro se encuentra precisamente el dispositivo de la persona, remite, como uno de sus focos de proveniencia, a la doble naturaleza de Cristo y a la teología trinitaria. En este sentido, no es casual que la estructura bipolar de la metafísica occidental, para Esposito, sea...

...reconocible hasta en la figura teológica de la Trinidad, cada vez que la Tercera persona es reconducida al fondo en favor de una relación exclusiva entre Padre e Hijo. No es fortuito que cada vez que el léxico teológico asume una connotación política, el Tres resulta reducido a la semántica del Dos, reforzando la dinámica en un esquema contrastivo (2013, p. 6).

Esposito tiene razón al afirmar que la tercera persona de la Trinidad, el Espíritu Santo, no ha gozado de la misma atención por parte de los teólogos y Padres de la Iglesia. Basta comparar las resoluciones de Nicea y Constantinopla para corroborar la importancia casi nula que posee el Espíritu Santo en el primero de estos Concilios, pero también la función ya más preponderante que desempeña en el segundo. Si bien es cierto, como asegura Esposito, que existe una "tendencia, no declarada pero de hecho practicada, a contrarrestar la fórmula triádica en un módulo dual, centrado en la relación jerárquica entre Padre e Hijo" (2013, p. 7), también es cierto que la tercera persona de la Trinidad ha terminado por ser completamente asimilada, aunque más no sea desde el fondo, por el dispositivo de la teología dogmática. Por eso creemos que la dislocación de la estructura personal de la teología no pasa tanto por la terza persona sino, como hemos sugerido con anterioridad, por la segunda. No es la hypostasis del Espíritu Santo, entonces, la que deconstruye la dicotomía de la máquina de la teología-política; es la segunda hypostasis, Cristo, la que, articulando dos naturalezas diversas pero no separadas, unidas pero no confundidas, abre - o puede llegar a abrir - la puerta a la no-persona. No sorprende, sin embargo, que Esposito haya encontrado en la figura de la tercera persona la posibilidad de subvertir la lógica del dispositivo dual de la teología-política. En este punto, hay que mencionar el importante trabajo de Émile Benveniste, al cual Esposito le dedica un capítulo de Terza persona. En los Problèmes de linguistique générale, Benveniste había distinguido las dos primeras personas de la tercera. Mientras que las dos primeras formaban parte de una misma lógica dual, la tercera se encontraba por así decir eximida y se ubicaba, por ende, en otro plano: "De la 3ra persona, un predicado también es enunciado, sólo que fuera del 'yo-tú'; esta forma es así exceptuada de la relación por la cual 'yo' y 'tú' se especifican. Por ello, la legitimidad de esta forma como 'persona' se encuentra puesta en cuestión" (1966, p. 228). Benveniste concluye, y Esposito con él, que "la '3ra persona' no es una 'persona'; incluso es la forma verbal que tiene por función expresar la no-persona" (1966, p. 228; el subrayado es 
de Benveniste). Por eso Benveniste puede definir al "tú" como la "persona no-yo" (cfr. 1966, p. 232), mientras que "él” o "ella" designan no-personas. O también: el "yo" es la persona subjetiva, el "tú" la persona no-subjetiva y el "él" o "ella" la nopersona (cfr. 1966, p. 232).

Sin embargo, los textos de Juan de Damasco que hemos analizado nos muestran que el peligro central de la teología no se encontraba en la tercera persona sino en la segunda. Por supuesto que no en lo que la segunda tenía de funcional a la lógica trinitaria, sino en lo que tenía, y sólo ella era capaz de tal cosa, de disruptivo. La bestia negra o la mancha ciega de la máquina de la teología-política no es el Espíritu Santo, la tercera persona, sino la cuarta. Pero la puerta de entrada (o de salida) a la cuarta persona, como hemos visto, es Cristo, la segunda hypostasis.

\subsection{The fourth person singular}

En 1959, Lawrence Ferlinghetti le dedica un poema a Allen Ginsberg titulado "He". Nos interesa ese texto de manera particular, puesto que en él Ferlinghetti habla del ojo y la voz de una cuarta persona del singular (the fourth person singular). Citamos algunos versos en los que se refiere a Ginsberg con palabras sugerentes:

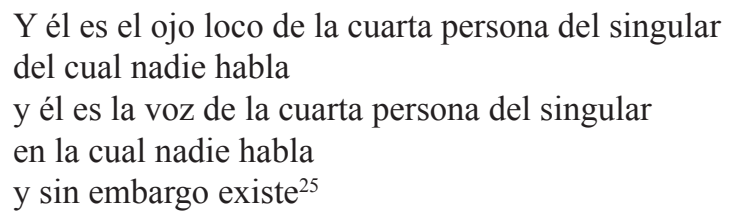

Ferlinghetti explica que esta voz desconocida "habla con una lengua animal [speaks with an animal tongue]" en "un lenguaje que ningún otro animal entiende [a language that no other animal understands]". En la cuarta persona del singular, además, la lengua ve y habla: "and his tongue sees and his tongue speaks". Pero lo más interesante de todo es que la cuarta persona del singular posee rasgos decididamente cristológicos. En efecto, no sólo se dice que Ginsberg "es amable como el cordero de Dios [is gentle as the lamb of God]", sino que incluso, en los versos finales del poema, se lo identifica, no ya con el Verbo hecho carne, sino con la carne hecha verbo:
Porque él ha llegado al fin del mundo
y es la trémula carne hecha verbo [flesh made word]
y dice el verbo que escucha en su carne
y el verbo es Muerte.

Así como la cuarta persona de la Trinidad, la carne hecha verbo, designa, desde un punto de vista ontológico, un extra-ser, asimismo designa, desde un punto de vista lógico, una forma no-personal extra o a-gramatical. No es casual, en este sentido, que Gilles Deleuze haya retomado la expresión de Ferlinghetti para designar el registro pre-personal y pre-individual de las singularidades que, como tales, se ubican "más

\footnotetext{
25 El poema se encuentra en Ferlinghetti 1999, pp. 134-137. Todos los versos citados corresponden a este poema, razón por la cual no indicamos en cada caso el número de página.
} 
allá de toda sintaxis" (cfr. 1993, pp. 16-17), en ese "límite que ya no es en sí mismo sintáctico o gramatical" (1993, p. 141). ${ }^{26}$ En efecto, en Logique du sens, Deleuze identifica a la cuarta persona del singular de Ferlinghetti con el plano potencial de las singularidades:

Las singularidades son los verdaderos acontecimientos trascendentales: lo que Ferlinghetti llama 'la cuarta persona del singular' [quatrième personne du singulier]. Lejos de que las singularidades sean individuales o personales, ellas presiden la génesis de los individuos y de las personas; se reparten en un potencial que no comporta para sí mismo ni Yo ni Mí mismo, sino que los produce actualizándose, efectuándose (1969, p. 125).

Este plano pre-individual y pre-personal, además, es el registro específico de los acontecimientos. Habíamos señalado que la cuarta persona designa un extra-Ser, ajeno por eso a la onto-teo-logía. Deleuze lo confirma cuando define al acontecimiento, es decir a la cuarta persona del singular que expresa las singularidades y que no por casualidad se identifica con la noción de fantôme (Deleuze 1969, p. 245-252), como un "aliquid, a la vez extra-ser e insistencia, [un] mínimo de ser que conviene a las insistencias (1969, pp. 33-34). El extra-Ser que define a la cuarta persona desde un punto de vista ontológico se corresponde, así, con la extra-gramaticalidad o la extrasintaxis que la define desde un punto de vista lógico. En efecto, la cuarta persona, advierte Deleuze, no está fuera del lenguaje, sino que "es el afuera [le dehors]" (cfr. 1993, p. 16, 141).

\section{Conclusión}

Hemos sugerido que la segunda hypostasis, Cristo, en tanto une sin confundir y distingue sin separar dos naturalezas, la divina y la humana, crea las condiciones de posibilidad de una dehiscencia entre lo visible y lo invisible o entre la materia y el espíritu. Juan de Damasco se refiere a esta carne, que no sería reductible ya a la carne humana y mucho menos a la realidad espiritual de la divinidad, como una suerte de aliquid que "no se ubicaría ni en la divinidad ni en la humanidad, y no sería llamado ni Dios ni hombre sino solamente Cristo: y la palabra Cristo no sería nombre de la persona" (De fide orthodoxa, III, 5). Este lugar paradójico, ajeno tanto a la tríada espiritual cuanto a la multiplicidad variopinta de la creación, concierne de manera específica a la cuarta persona. Pero ¿cómo pensar esta carne?, ¿esta subsistencia ni humana ni divina, ni material ni espiritual?

Lejos de nosotros ofrecer una respuesta exhaustiva a tamaña pregunta. Sin embargo, quisiéramos dejar planteada la posibilidad de pensar esta carne y, más en general, este topos paradójico e intermedio, como el reino específico de las imágenes. En efecto, las imágenes - y por ende también la imaginación - han ocupado, a lo largo de las líneas predominantes de la metafísica occidental, ese lugar intermedio

26 René Schérer ha mostrado la insuficiencia de la tercera persona a la hora de explicar la noción deleuziana de "impersonal": "el impersonal deleuziano admite sólo parcialmente una traducción o una transposición lingüística. Sobrepasa toda lingüística hacia el sentido. Concierne a la emergencia de un mundo que necesita para expresarse un lenguaje distinto al de las personas, por más que fuese la tercera. Exige una cuarta, específica de las 'singularidades' sobre ese plano de inmanencia que también puede ser llamado trascendental, pues toda trascendencia, comenzando por la de las personas, es allí abolida” (2012, p. 35). 
entre lo corpóreo y lo incorpóreo, entre lo sensible y lo inteligible o entre la materia y el espíritu. No es casual, además, que Cristo, siendo el mediador entre Dios y los hombres se presente precisamente, según el célebre pasaje de Pablo, como "la imagen [eikōn] del Dios invisible" (1 Col. 15:20).

Ahora bien, creemos que la carne que está en juego en la cuarta persona es una carne fantasmática, una carne imaginaria. La teología cristiana ha conocido este tipo de carne, casi en el mismo momento en el que comenzaban a constituirse los pilares doctrinales, alrededor de los siglos II-III, por intermedio de uno de los herejes más combatidos del momento: Marción. ${ }^{27}$ En este sentido, las refutaciones de Tertuliano, un autor preocupado además por demostrar la realidad humana de la carne de Cristo, resultan decisivas. ${ }^{28}$ Marción, y de algún modo también el movimiento docetista en general, sostenía que Cristo no había asumido una carne humana sino una mera apariencia fantasmática e ilusoria. ${ }^{29}$ Según Marción, explica Tertuliano, Cristo no era sino un fantasma: "él [Marción] sostenía que Cristo es un fantasma [phantasma vindicans Christum]" (Adversus Marcionem, III, 8, 1). ${ }^{30} \mathrm{O}$ también, en la medida en que la carne asumida por Cristo era de naturaleza fantasmática y no humana, no podía de ninguna manera sufrir ni padecer, pues "un fantasma no puede verdaderamente sufrir [vere autem pati phantasma non potuit]" (Adversus Marcionem, III, 8, 5). Si esto fuese así, continúa Tertuliano, "toda la obra de Dios se vería subvertida [Eversum est igitur totum dei opus]" (ibid.). Marción, por lo tanto, nos presenta otro Cristo, inaceptable para Tertuliano y para la cristología incipiente, cuya naturaleza carnal al límite de toda noción de naturaleza - es meramente fantasmática: "Si es falso que, en tanto fantasma [phantasma], Cristo sufrió, entonces es también falso que nació. Tales son los argumentos de Marción por los cuales nos presenta otro Cristo [alium efficit Christum]" (Adversus Marcionem, III, 11, 8). Como bien ha mostrado Judith M. Lieu: "Para Tertuliano, el término [fantasma] denota al mismo tiempo imitación y engaño - de aquí su pregunta retórica de por qué Jesús no fue 'un fantasma de Dios' [a phantasm of God]; el término implica lo ilusorio (putativus) como opuesto a lo verdadero" $\left(2015\right.$, p. 374). ${ }^{31}$

27 Como se sabe, no se han conservado escritos de Marción. En nuestro caso, nos interesa sobre todo la lectura crítica - y por ende la reconstrucción intencionada y estratégica - que realiza Tertuliano, particularmente en Adversus Marcionem. Sobre el pensamiento y la curiosa figura de Marción, cfr. Harnack (1924); Lieu (2015); Orbe (1995), vol. I, pp. 34-38, 107-108; (1995a), vol. II, pp. 250-268.

28 No es casual que para Esposito el dispositivo de la persona, en su vertiente teológica, encuentre uno de sus focos de proveniencia en la obra de Tertuliano: "Es indudable que el texto en el cual el término 'persona' asume por primera vez una precisa connotación teológica es el tratado de Tertuliano Adversus Praxeam" (2013, p. 91).

29 En efecto, explica Judith M. Lieu en Marcion and the Making of a Heretic. God and Scripture in the Second Century: "El término preferido por Tertuliano para describir al Jesús de Marción es fantasma [phantasma]; aunque no es exclusivo de los libros contra Marción, se lo encuentra en ellos de forma predominante" (2015, p. 374).

30 Para las citas de Tertuliano utilizamos la edición crítica de René Braun en la colección Sources Chrétiennes.

31 El phantasma, y no el corpus ni la caro, es el verdadero punto de desencaje de la cristología dogmática, la eversio, la subversión o, mejor aún, la perversión del opus Dei. Pero para llegar al corazón del fantasma, es preciso ir incluso más allá de Marción - y, de la misma manera, más allá de Tertuliano - y leerlo, de algún modo, contra sí mismo. Para Marción, el Cristo fantasmático se identifica con la realidad espiritual de la divinidad. Cristo es divino, y justamente por eso no puede asumir una naturaleza corpórea. Por tal motivo, Tertuliano se esfuerza por demostrar que la redención del hombre implica por necesidad la condición también humana del Hijo de Dios. Si para Marción Cristo es sólo divino, para Tertuliano (y para el canon de la cristología ortodoxa que se estaba constituyendo) es a la vez humano y divino. Pero creemos que el verdadero peligro para la teología, peligro que se oculta en la noción de phantasma, radica en su condición irreductible a las polaridades propias de la tradición occidental. In extremis, Cristo sería un phantasma carnis y a la vez un phantasma Dei. 
Ahora bien, quisiéramos sugerir, entonces, que este alius Christus que nos presenta Marción, según la reconstrucción crítica de Tertuliano, designa con precisión el aspecto disyuntivo de la segunda hypostasis. Este Cristo fantasmático, este fremden Gott (cfr. Harnack 1924), irreductible a la materia y al espíritu, a la divinidad y a la humanidad, representa la dehiscencia que corresponde a la cuarta persona. El Cristo de Marción - tal como nosotros lo entendemos, es decir, de algún modo leyendo a Marción contra Marción - es el Cristo como disiunctio, como la apertura de un espacio más allá de lo humano y de lo divino, de lo material y de lo espiritual, de lo visible y de lo invisible, en suma, más allá del Ser (tal como ha sido pensado por la teología y la metafísica del Occidente). ${ }^{32}$ A lo largo de lo que Martin Heidegger ha llamado la historia de la metafísica occidental, este lugar paradójico y quiasmático, irremediablemente externo a lo sensible y lo inteligible, ha coincidido con el mundo de las imágenes y de los fantasmas, cuyo reino paradigmático no es ni el reino de los cielos ni el de la tierra, ni el de Dios ni el del hombre, sino el reino de los sueños. No es casual, por eso mismo, que Judith Lieu, comentando la noción de phantasma en el Adversus Marcionem de Tertuliano, agregue: “Fantasma' era utilizado también para referirse a las figuras que aparecían en sueños y en visiones, aunque no hay aún un consenso sobre la naturaleza de su existencia substancial, e incluso sobre si deberían ser consideradas como 'reales"' (2015, p. 375).

El alius Christus de Marción, el Cristo como fantasma, nos introduce pues en una topografía extremadamente singular, ni humana ni divina, ni material ni espiritual, una topografía onírica que sólo puede ser recorrida por la cuarta persona. El fantasma es la cuarta persona: la mancha ciega de la lógica trinitaria. Si volvemos ahora a Juan de Damasco, podemos concluir que este aliquid que "no se ubicaría ni en la divinidad ni en la humanidad, y [que] no sería llamado ni Dios ni hombre sino solamente Cristo: y la palabra Cristo no sería nombre de la persona" (De fide orthodoxa, III, 5), no es otra cosa que el fantasma, es decir la puerta que nos conduce al reino fantasmático de los sueños. La palabra Cristo, así, designaría, en su vector disyuntivo o dehiscente, no ya la persona, ni siquiera la tercera, sino la no-persona o, mejor aún, la cuarta persona de la Trinidad: tetarton prosōpon en tē Triadi.

\section{Referencias bibliográficas}

Anastos, M. V. (1979): Studies in Byzantine Intellectual History, London, Variorum Reprints. Ayres, L. (2004): Nicaea and Its Legacy. An Approach to Fourth-Century Trinitarian Theology, Oxford, Oxford University Press.

Barasch, M. (1995): Icon. Studies in the History of an Idea, New York - London, New York University Press.

Belting, H. (2009): Imagen y culto. Una historia de la imagen anterior a la edad del arte, Madrid, Akal.

La expresión phantasma Dei figura, de hecho, en Adversus Marcionem III, 8. Si Cristo es un phantasma carnis, se pregunta allí Tertuliano, ¿por qué no sería también un phantasma Dei? Vemos entonces que el phantasma no se confunde ni con la caro ni con el spiritus, ni con homo ni con Deus.

32 Este doble sentido del dispositivo cristológico concierne a dos tipos de imágenes: el eikōn, es decir la imagen que asegura la coniunctio entre lo divino y lo humano, y el phantasma, la imagen - la carne imaginal - que se insinúa en la dehiscencia o la disiunctio de la segunda hypostasis. Por razones de extensión, no podemos desarrollar aquí este asunto, pero puede consultarse Prósperi (2019), pp. 205-312. 
Benveniste, É. (1966): Problèmes de linguistique générale, Paris, Gallimard, Tome I.

Braun, R. (1994): Tertullien. Contre Marcion. Tome III. Livre III. Introduction, texte critique, traduction, notes et index des livres I-III par R. Braun, Paris, Éditions du Cerf, (Sources Chrétiennes, 399).

Cross, R. (2000): "Perichoresis, Deification, and Christological Predication in John of Damascus", Mediaeval Studies, Volume 62, pp. 69-124.

Brubaker, L. (2012): Inventing Byzantine Iconoclasm, London, Bristol Classical Press.

Deleuze, G. (1969): Logique du sens, Paris, Éditions de Minuit.

Deleuze, G. (1993): Critique et clinique, Paris, Les Éditions de Minuit.

Derrida, J. (1967): De la grammatologie, Paris, Éditions de Minuit.

Di Berardino, A. (ed.) (2000): Patrologia Vol. V. Dal Concilio di Calcedonia (451) a Giovanni Damasceno († 750). I Padri orientali, Genova, Casa Editrice Marietti.

Esposito, R. (2007): Terza persona. Politica della vita e filosofia dell'impersonale, Torino, Einaudi.

Esposito, R. (2013): Due. La macchina della teologia politica e il posto del pensiero, Torino, Einaudi.

Fazzo, V. (1998): “Introduzione”, en Juan de Damasco, La fede ortodossa, Roma, Città Nuova Editrice.

Ferlinghetti, L. (1999): “He”, en D. Allen (ed.), The New American Poetry, 1945-1960, Berkeley - Los Angeles - London, University of California Press, pp. 134-137.

Giakalis, A. (2005): Images of The Divine: The Theology of Icons at The Seventh Ecumenical Council, Leiden - Boston, Brill.

Grillmeier, A. (1975): Christ in Christian Tradition. From the Apostolic Age to Chalcedon (451), Vol. I, Atlanta, John Knox Press.

Harnack, A. (1924): Marcion: Das Evangelium vom fremden Gott. Eine Monographie zur Geschichte der Grundlegung der katholischen Kirch, Leipzig, J. C. Hinrichsche Buchhandlung.

Henry, M. (2000): Incarnation. Une philosophie de la chair, Paris, Éditions du Seuil.

Hussey, J. M. (1990): The Orthodox Church in the Byzantine Empire, Oxford, Oxford University Press.

Kelly, J. N. D. (1968): Early Christian Doctrines, London, Adam \& Charles Black.

Kotter, B. (1975): Die Schriften des Johannes von Damaskos, Berlin - New York, Walter De Gruyter.

Krasmüller, D. (2001): "Leontius of Jerusalem, a theologian of the 7th century", JTS, 52, pp. 637-657.

Krasmüller, D. (2005): "Conflicting anthropologies in the Christological discourse at the end of Late Antiquity: the case of Leontius of Jerusalem's Nestorian adversary”, JTS, 56, pp. 413-447.

Leoncio de Jerusalén, Contra Nestorianos, en J. P. Migne, PG, vol. 86.

Lieu, J. M. (2015): Marcion and the Making of a Heretic. God and Scripture in the Second Century, New York, Cambridge University Press.

Lossky, V. (1967): À l'image et à la ressemblance de Dieu, Paris, Aubier - Montaigne.

Louth, A. (2002): St. John Damascene, Oxford, Oxford University Press.

Louth, A. (2007): “St. John Damascene as Monastic Theologian", The Downside Review, Volume 125, pp. 197-220.

Ludueña Romandini, F. (2009): "Eternidad, espectralidad, ontología: hacia una estética trans-objetual”, en A. Badiou, Pequeño manual de inestética, Buenos Aires, Prometeo. 
Mansi, J. D. (1767): Sacrorum Conciliorum Nova Amplissima Collectio, Florencia, Expensis Antonii Zatta Veneti, Vol. 13.

Meinong, A. (1904): Untersuchungen zur Gegenstandstheorie und Psychologie, Leipzig, Verlag von Johann Ambrosius Barth.

Meinong, A. (1907): Über die Stellung der Gegenstandstheorie im System der Wissenschaften, Leipzig, R. Voigtländer.

Merleau-Ponty, M. (1964): Le visible et l'invisible, Paris, Gallimard.

Orbe, A. (1995): La teología dei secoli II e III. Il confronto de la Grande Chiesa con lo gnosticismo, Vol. I, Roma, Editrice Pontificia Università Gregoriana.

Orbe, A. (1995a): La teología dei secoli II e III. Il confronto de la Grande Chiesa con lo gnosticismo, Vol. II, Roma, Editrice Pontificia Università Gregoriana.

Price, R. y Gaddis, M. (eds.) (2005): The Acts of the Council of Chalcedon, Liverpool, Liverpool University Press.

Price, R. y Whitby, M. (eds.) (2009): Chalcedon in Context. Church Councils 400-700, Liverpool, Liverpool University Press.

Prósperi, G. (2018). La respiración del Ser. Apnea y ensueño en la filosofía hegeliana, Buenos Aires, Miño y Dávila editores.

Prósperi, G. (2019). La máquina óptica. Antropología del fantasma y (extra)ontología de la imaginación, Buenos Aires, Miño y Dávila editores.

Régnon, Th. (1892). Etudes de théologie positive sur la Trinité. Vol. 1. Exposé du dogme, Paris, Retaux.

Schérer, R. (2012): Miradas sobre Deleuze, Buenos Aires, Editorial Cactus.

Studer, B. (1993): Trinity and Incarnation. The Faith of the Early Church, Minnesota, The Liturgical Press.

Timbie, J. (2007): “Coptic Christianity”, en Ken Parry (ed.), The Blackwell Companion to Eastern Christianity, Oxford, Blackwell Publishing Ltd., pp. 94-116.

Unger, D. (1948): “The Incarnation - A Supreme Exaltation for Christ according to St. John Damascene", Franciscan Studies, Vol. 8, No. 3, pp. 237-249.

Zhyrkova, A. (2009): "Hypostasis - The Principle of Individual Existence in John of Damascus", Journal of Eastern Christian Studies, 61(1-2), pp. 101-130. 